\title{
CXXXIX. CHARACTERISTICS OF HIGHLY ACTIVE VITAMIN A PREPARATIONS.
}

\author{
BY ISIDOR MORRIS HEILBRON, ROBERT NORMAN HESLOP, \\ RICHARD ALAN MORTON AND ERIC TAYLOR WEBSTER, \\ The Department of Chemistry, University of Liverpool, \\ AND \\ JOSE LORENZO REA AND JACK CECIL DRUMMOND, \\ The Department of Physiology and Biochemistry, \\ University College, London.
}

(Received May 17th, 1932.)

In a series of papers emanating from these laboratories during the past five years unequivocal spectroscopic data for vitamin A have been established, and the ground has been cleared for a final comprehensive attack on the problem of isolating the vitamin and establishing its constitution. The present communication embodies the results of work carried out during the last 18 months, and leads us to the view that a definite solution of the problem is now in sight, a view supported by the recent highly important and illuminating publications of Karrer, Morf and Schöpp [1931, 1, 2], to which further reference will be made later.

Vitamin A, both in liver oils and concentrates, exhibits a broad continuous absorption band in the ultra-violet, extending from 260 to $380 \mathrm{m \mu}$, and exhibiting a maximum near $328 m \mu$. The intensity of this band can easily be measured and used as a definite quantitative test for the potencies of oils and concentrates. Vitamin A also shares with a variety of polyene substances the power of giving a blue solution with a saturated solution of anhydrous antimony trichloride in chloroform. This colour test gains in specificity when the spectral absorption of the blue solution can be accurately described. As a matter of convenience attention may be concentrated on the points of maximum absorption described in terms of intensity and spectral location ${ }^{1}$. Thus the blue solution obtained with vitamin A exhibits two maxima at 617 and $583 m \mu$ respectively, the former being generally much more intense than the latter, which it tends to mask. In unsaponified oils the maxima are displaced to 606 and $573 m \mu$ respectively, and here the longer wave-length absorption

\footnotetext{
1 The notation used in this paper is necessarily a little different from that employed in spectroscopic studies on pure substances. The usual method is to state the maximum molecular extinction coefficient $e$, defined by $E=\log I_{0} / I=e c d$. ( $\left(I_{0}\right.$ is intensity of incident light, $I$ is intensity of emergent light, $E$ is extinction, $c=$ molar concentration, $d=$ thickness in $\mathrm{cm}$.) In this work $E_{1 \mathrm{~cm}}^{1 \%}$ refers to $\log I_{0} / I$ at a wave-length maximum, using a solution containing $1 \%$ of vitamincontaining substance and a $1 \mathrm{~cm}$. cell.
} 
suffers considerable but variable diminution in intensity as a result of the inhibiting action of certain normal constituents of fish-liver oils.

In a number of oils and concentrates the presence of additional chromogenic substances manifests itself in the colour test by giving rise to other maxima, among which one at $693 \mathrm{m \mu}$ occurs with considerable regularity [Morton, Heilbron and Thompson, 1931]. With such criteria of vitamin A available it seemed obvious that, provided a satisfactory method of isolation of the vitamin could be achieved, pure preparations from the livers of various species of both fishes and of mammals should all exhibit the maxima at 328 , 617 and $583 \mathrm{m \mu}$, each at its own limiting maximum intensity, if all three were indeed properties of vitamin A itself. On the other hand, if any one of the three maxima appeared with relatively diminished intensity, the interpretation would have to be reconsidered. It by no means necessarily follows, however, even if constant values are reached, that vitamin A has been obtained as a homogeneous substance, although one condition of purity is apparently satisfied. It is this stage which we have now reached in our investigations; concentrates of equal potency derived from different sources have been obtained and have proved incapable of being increased in potency by any process calculated to result in a separation of the constituents of a mixture.

Table I.

\begin{tabular}{|c|c|c|c|}
\hline Material & $E_{1 \%}^{1 \%} 328 m \mu$ & $E_{1 \mathrm{~cm} .}^{1 \%} 617 m \mu$ & $E_{1 \mathrm{~cm} .}^{1 \%} 580 m \mu$ \\
\hline Average cod-liver oil & $0 \cdot 78^{*}$ & $0 \cdot 92$ & $0 \cdot 70$ \\
\hline Typical halibut-liver oils $(a)$ ) & $4 \cdot 25$ & $7 \cdot 5$ & $6 \cdot 0$ \\
\hline$" \quad, \quad \quad(b)\}$ winter catches & $3 \cdot 5$ & $6 \cdot 2$ & $4 \cdot 8$ \\
\hline$\Rightarrow \quad, \quad, \quad(c)\}$ & $15 \cdot 6$ & $32 \cdot 0$ & $16 \cdot 7$ \\
\hline Total non-sap. (9 \%) from $(c)$ & 380 & 720 & 460 \\
\hline Rich halibut oil $(d)$ & 35 & 70 & 47 \\
\hline $\begin{array}{l}\text { Non-sap. of }(d) \text { (approx. } 2 \% \text { ) after freezing } \\
\text { at }-50^{\circ}\end{array}$ & 1150 & 3300 & 1800 \\
\hline Rich halibut oil $(e)$ & 70 & 148 & 85 \\
\hline Total non-sap. $(8 \%)$ of $(e)$ & 550 & 1150 & 600 \\
\hline (e) deprived of sterol at $-10^{\circ}(4.7 \%)$ & 1060 & 2210 & 1110 \\
\hline (e) after treatment at $-50^{\circ}$ & 1150 & 3020 & 1450 \\
\hline
\end{tabular}

Earlier work had convinced us that if vitamin A were to be prepared in a state approaching purity, it was certainly desirable, if not indeed absolutely essential, to start from highly active oils. In conjunction with Dr J. A. Lovern of the Torry Research Station, Aberdeen, a large number of fish-liver oils of different species have been examined under conditions most favourable to conservation of the vitamin and, as a result, enormous variations in potency have emerged not only between the oils from various species but also between different specimens of oil from a single species. Apparently the potency of some fish-liver oils is much lower in the winter than in summer, but this seasonal variation provides, we believe, only a partial explanation of the wide deviations. From the mass of data in our hands, one fact very soon impressed 
itself, namely that of all fish-liver oils studied, that from the halibut is outstanding in showing occasionally unusually high potency, and it is such oils that we have generally employed as starting material in this investigation. The importance of a careful selection of raw material will be evident from Table I, which illustrates by means of the spectroscopic maxima the wide variations observed in halibut-liver oils.

The general method of saponification adopted by us consisted in heating the oil (500 g.) with $12 \%$ alcoholic potash $\left(1250 \mathrm{cc}\right.$.) at $75^{\circ}$ for 1 hour in an atmosphere of nitrogen under slightly reduced pressure, during which period approximately half the alcohol distilled over. The cooled solution was diluted with distilled water $(6000 \mathrm{cc}$.) and the unsaponifiable matter removed by repeated extraction with ether. After drying over anhydrous sodium sulphate and removal of solvent, the residue was dissolved in hot methyl alcohol (150 cc.) and left to stand, when the bulk of the sterols (mainly cholesterol) present in the mixture separated and were removed at the pump. The filtrate was reduced to half bulk in an atmosphere of nitrogen, and cooled to $-10^{\circ}$, when more sterol crystallised and was removed. The residual solution was then cooled to about $-50^{\circ}$ in a mixture of solid carbon dioxide and ether, and after standing for some time rapidly filtered through a jacketed sintered filter maintained at the same temperature. The residue, which had a comparatively low vitamin content, was rejected. The filtrate was diluted largely with water and extracted with light petroleum (B.P. $40-50^{\circ}$ ) and the solvent finally removed from the dried extract, which was then heated at $70^{\circ}$ in a high vacuum. The stages in the concentration of the vitamin, starting from two rich halibut oils $(d)$ and $(e)$ are reproduced in Table $\mathbf{I}$.

An estimation of the sterol content of $(e)$, after treatment at $-50^{\circ}$, by means of digitonin showed that approximately $3 \%$ was present. Resaponifications of different samples with both sodium ethoxide and sodium methoxide were carried out, but these failed to produce products of increased potency. For the further concentration of the vitamin attempts were made to separate it both by methods involving the distribution between two solvents and also by adsorption on kieselguhr, calcium carbonate and kaolin, but these processes failed to effect any definite increase in potency as measured spectroscopically. It was therefore decided to resort to distillation in a very high vacuum. Attempts to distil vitamin A have previously been reported by Drummond and Baker [1929], who employed pressures near $0.01 \mathrm{~mm}$., but found that under these conditions the vitamin was largely destroyed in the process. In the hope of avoiding this decomposition a special apparatus was constructed (see Fig. 1) whereby fractional distillation of the already very rich concentrates could be carried out at a pressure certainly below $0.0001 \mathrm{~mm}$. The halibut concentrate $(10 \mathrm{~g}$.) was introduced into the boat, which was then heated to between 150 and $155^{\circ}$, when distillation commenced. The main fraction, which formed a heavy golden-yellow oil ( $c$ in Table II) was collected over a period of $3 \frac{1}{2}$ hours. A spectrographic examination of this apparently 


\section{VITAMIN A}

\section{Table II.}

\begin{tabular}{|c|c|c|c|c|c|}
\hline \multirow[b]{2}{*}{ Material } & \multirow{3}{*}{$\begin{array}{l}\text { Conden. } \\
\text { sation } \\
\text { temp. } \\
-\end{array}$} & \multirow{2}{*}{$\begin{array}{l}\text { Weights } \\
\text { of } \\
\text { fractions } \\
\text { g. }\end{array}$} & \multicolumn{3}{|c|}{$E_{1 \mathrm{~cm}}^{1 \%}$} \\
\hline & & & $617 m \mu$ & $580 m \mu$ & $328 m \mu$ \\
\hline $\begin{array}{l}\text { Sterol-freed non-sap. } \\
\text { from halibut-liver oil }\end{array}$ & & 10 & 2350 & 1550 & 1000 \\
\hline $\begin{array}{l}\text { Distillation fractions: } \\
(a)\end{array}$ & $25-50^{\circ}$ & $0 \cdot 14$ & $\begin{array}{l}480 \\
(624 \\
m \mu)\end{array}$ & $\begin{array}{l}400 \\
(567 \\
m \mu)\end{array}$ & $\begin{array}{l}\text { The ultra-violet absorption shows } \\
\text { a clear maximum at } 285 \text {, a pro- } \\
\text { nounced inflexion at } 330 \text { and a } \\
\text { small inflexion near } 371 \mathrm{~m} \mu\end{array}$ \\
\hline & & & & & $E_{1 \mathrm{~cm} .}^{1 \%}\left\{\begin{array}{l}285 m \mu=271 \\
330 m \mu=203\end{array}\right.$ \\
\hline (b) & $50-80^{\circ}$ & $0 \cdot 11$ & 410 & 340 & $E_{1 \mathrm{~cm} .}^{1 \%}\left\{\begin{array}{l}290 m \mu=250 \text { maximum } \\
328 m \mu=170 \text { inflexion. }\end{array}\right.$ \\
\hline & & & & & $\begin{array}{l}\text { There are feeble indications of } \\
\text { finer structure in the selective } \\
\text { absorption. }\end{array}$ \\
\hline (c) & $80-110^{\circ}$ & $4 \cdot 9$ & 1760 & 1160 & $\begin{array}{l}\text { The general shape of the absorp- } \\
\text { tion curve is similar to the } \\
\text { normal vitamin A curve, but } \\
\text { more selective absorption is } \\
\text { superimposed, sharp maxima } \\
\text { occurring at } 393,368,348,330 \text {, } \\
313.5 \text { and } 297 m \mu \\
E_{1}^{1 \%} \text { cn. } 330 m \mu=710\end{array}$ \\
\hline$(d)$ & $110-120^{\circ}$ & 0.57 & 600 & 400 & $\begin{array}{l}\text { The same fine structure is } \\
\text { shown }\end{array}$ \\
\hline & & & & & $E_{1 \mathrm{~cm} .}^{1 \%} 330 m \mu=265$ \\
\hline $\begin{array}{l}\text { (e) (semi-solid yellow } \\
\text { wax; crystals of } \\
\text { cholesterol) }\end{array}$ & $120-140^{\circ}$ & $0 \cdot 15$ & 250 & 160 & $\begin{array}{l}\text { In addition to an inflexion near } \\
370 m \mu \text {, the absorption appears } \\
\text { to consist of a fusion of two con- } \\
\text { tinuous bands with maxima re- } \\
\text { spectively at } 330 \text { and } 290 m \mu \text {. } E \\
\text { in each case approx. } 100 \text {. Small } \\
\text { quantities of substances exhi- } \\
\text { biting the narrow bands also } \\
\text { occur. }\end{array}$ \\
\hline$(f)$ & $140-155^{\circ}$ & $4 \cdot 2$ & $\begin{array}{l}180 \\
(610 \\
m \mu)\end{array}$ & $\begin{array}{c}180 \\
(578 \\
m \mu)\end{array}$ & $\begin{array}{l}\text { A very flat maximum occurs at } \\
290 m \mu . E_{1}^{1 \%} \mathrm{~cm}=65 \text {, but there is } \\
\text { little evidence of the narrow } \\
\text { bands }\end{array}$ \\
\hline
\end{tabular}

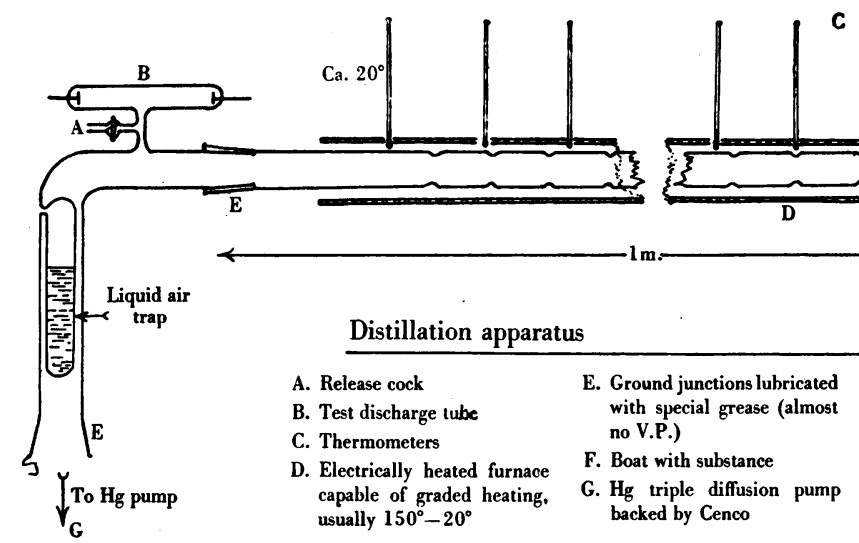

Fig. 1. 
Table III.

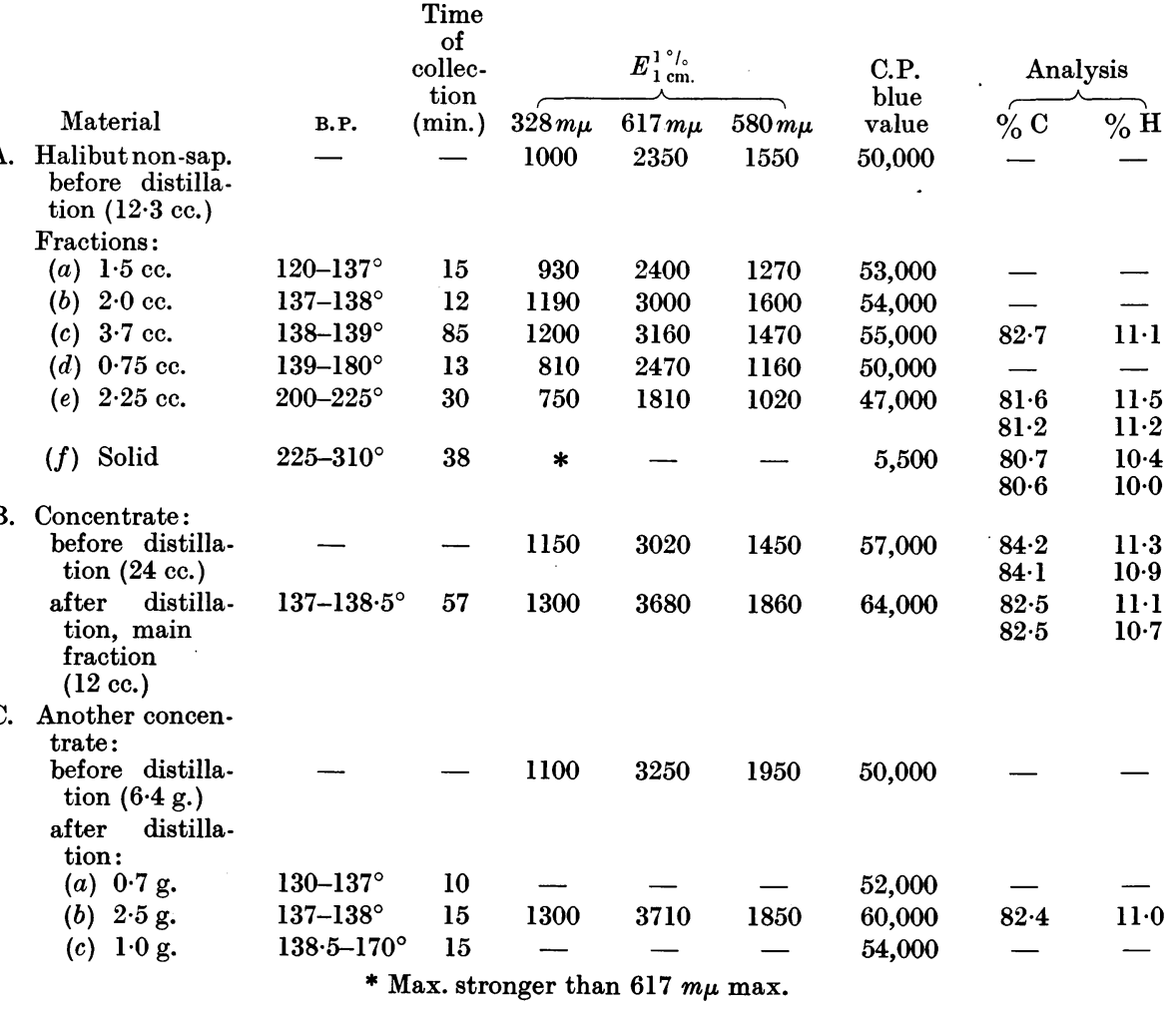

undecomposed distillate revealed that actually readily detectable changes had occurred, for in place of the typical continuous ultra-violet absorption band at $328 \mathrm{~m} \mu$ an absorption curve showing well defined narrow bands was now exhibited. These bands were also found when the vitamin was dissolved in alcoholic hydrogen chloride and in the material obtained on the regeneration of a vitamin A concentrate from the blue antimony trichloride colour test [Edisbury et al., 1932]. The experiment was repeated with a richer starting material $\left(E_{1 \mathrm{~cm} .}^{1 \%} 328 m \mu=1150\right)$ with similar results; it thus appeared plausible that the molecular rearrangement involved might be due to the prolonged period of heating, possibly combined with some catalytic effect due to the large surface of glass with which the vapour comes into contact. With the very helpful collaboration of Dr F. H. Carr and Mr W. Jewell of British Drug Houses, Ltd., the distillation of rich halibut oil concentrates was also carried out in a new type of molecular still, whereby rapid fractional distillation could be effected at a pressure below $0.00001 \mathrm{~mm}$. Under these conditions the vitamin distils without decomposition or molecular change, giving a main fraction, B.P. $137-138^{\circ}$, having considerably enhanced potency. The results of typical distillations are summarised in Table III. Redistillation of the best fraction resulted in a slight decrease of potency as measured 
spectroscopically and it would thus seem that the method had been utilised to the point of maximum efficacy. In order to test this point on different material a sturgeon-liver oil was employed which, although initially not particularly rich in vitamin A, after saponification and freezing provided an unsaponifiable fraction of very high potency. The distillation of this is recorded in Table IV, from which it will be seen that the spectrographic values are in excellent agreement with those obtained from the halibut concentrates.

Table IV.

\begin{tabular}{|c|c|c|c|c|c|c|c|c|}
\hline \multirow[b]{2}{*}{ Material } & \multirow[b]{2}{*}{ B.P. } & \multirow{2}{*}{$\begin{array}{l}\text { Time } \\
\text { of } \\
\text { collec- } \\
\text { tion } \\
\text { (min.) }\end{array}$} & \multicolumn{3}{|c|}{$E_{1 \mathrm{~cm} .}^{1 \%}$} & \multirow{2}{*}{$\begin{array}{l}\text { C.P. } \\
\text { blue } \\
\text { value }\end{array}$} & \multicolumn{2}{|c|}{ Analysis } \\
\hline & & & $328 m \mu$ & $617 m \mu$ & $580 m \mu$ & & $\% \mathrm{C}$ & $\% \mathrm{H}$ \\
\hline $\begin{array}{l}\text { A. Sturgeon-liver } \\
\text { oil }\end{array}$ & - & - & 18 & 39 & 19 & - & - & - \\
\hline $\begin{array}{l}\text { Total non-sap. } \\
(4 \cdot 8 \%)\end{array}$ & - & - & 200 & 500 & 290 & - & - & - \\
\hline $\begin{array}{l}\text { Non-sap. after } \\
\text { treatment at } \\
-50^{\circ}(1 \quad \%) \\
(6 \cdot 2 \text { g. })\end{array}$ & - & - & 1080 & 3380 & 1680 & 57,000 & $\begin{array}{l}82 \cdot 1 \\
82 \cdot 3\end{array}$ & $\begin{array}{l}10 \cdot 7 \\
10 \cdot 5\end{array}$ \\
\hline $\begin{array}{l}\text { After high vac. } \\
\text { distillation: } \\
\text { (1) } 1 \mathrm{cc} \text {. }\end{array}$ & & & & & & & & \\
\hline $\begin{array}{l}\text { (1) } 1 \text { cc. } \\
(2) 1 \mathrm{cc} .\end{array}$ & $\begin{array}{l}120^{\circ} \\
120-137^{\circ}\end{array}$ & $\begin{array}{r}15 \\
5\end{array}$ & $\overrightarrow{1300}$ & $\overline{3950}$ & $\overline{1990}$ & 二 & 二 & - \\
\hline (3) $2 \cdot 8 \mathrm{cc}$. & $137-138^{\circ}$ & 12 & 1330 & 4200 & 2130 & 64,000 & $\begin{array}{l}82 \cdot 8 \\
82 \cdot 6\end{array}$ & $\begin{array}{l}10 \cdot 9 \\
10 \cdot 7\end{array}$ \\
\hline $\begin{array}{l}\text { B. Mammalian- } \\
\text { liver fat }\end{array}$ & - & - & 235 & 780 & 470 & 11,000 & - & - \\
\hline $\begin{array}{l}\text { Non-sap. after } \\
\text { treatment at } \\
-50^{\circ}(20 \text { \% }) \\
(9 \cdot 2 \mathrm{~g} .)\end{array}$ & - & - & 1000 & 2750 & 1370 & - & $82 \cdot 4$ & $11 \cdot 1$ \\
\hline $\begin{array}{l}\text { After distillation: } \\
\text { Fraction: }\end{array}$ & & & & & & & & \\
\hline $\begin{array}{l}\text { (1) } 2.7 \mathrm{~g} . \\
\text { (2) } 1 \cdot 2 \text { g. }\end{array}$ & $\begin{array}{l}143-149^{\circ} \\
149-150^{\circ}\end{array}$ & $\begin{array}{l}10 \\
10\end{array}$ & 1250 & 3620 & 2350 & 50,000 & $\stackrel{82 \cdot 7}{-}$ & $11 \cdot 1$ \\
\hline (3) $0.9 \mathrm{~g}$. & $150-165^{\circ}$ & 10 & - & - & - & - & - & - \\
\hline (4) $4.2 \mathrm{~g}$. & Above $165^{\circ}$ & - & - & - & - & 4,200 & - & 一 \\
\hline
\end{tabular}

In order to extend these results it seemed desirable to attempt a concentration of vitamin A from an oil of mammalian source, and we are indebted to Messrs Lever Brothers Ltd. for kindly placing a partially concentrated mammalian extract at our disposal. This was again worked up in the manner already described and gave a highly viscous dark unsaponifiable fraction, the spectrographic data for which (see Table V) were in good agreement with the values obtained from similar fractions of the halibut and sturgeon concentrates. Owing to the very high viscosity of the product the distillation into fractions in this case was rather less sharp, but it will be observed that the main fraction again gives substantially the same values for the 328,617 and $580 m \mu$ bands as with the fish-liver distillates. By thus obtaining from totally distinct sources concentrates of constant potency a considerable advance has been made. Certain difficulties still remain before proof of homogeneity in the highly active fractions can be affirmed. In the first place, the evidence 


\begin{tabular}{|c|c|c|c|c|c|}
\hline \multirow[b]{2}{*}{ Material } & \multicolumn{3}{|c|}{$\overbrace{1}^{E_{1 \%}^{1 \%}}$} & \multicolumn{2}{|c|}{$\overbrace{}^{\text {Analysis }}$} \\
\hline & $328 m \mu$ & $617 m \mu$ & $580 m \mu$ & $\% \mathrm{C}$ & $\% \mathrm{H}$ \\
\hline Halibut-liver oil non-sap. & 1000 & 2350 & 1550 & - & - \\
\hline Small scale adsorption exp. (middle layer) (3 g.) & 1100 & 2730 & 1470 & $\begin{array}{l}81 \cdot 3 \\
81 \cdot 2\end{array}$ & $\begin{array}{l}10 \cdot 7 \\
10 \cdot 5\end{array}$ \\
\hline Large scale adsorption exp. (middle layer) $(17 \cdot 5$ g.) & 1050 & 2470 & 1220 & - & - \\
\hline Halibut-liver oil non-sap. distillate & 1300 & 3710 & 1850 & $82 \cdot 4$ & $11 \cdot 0$ \\
\hline Adsorption of distillate & 1350 & 4350 & 2350 & $83 \cdot 2$ & $10 \cdot 8$ \\
\hline Repeat adsorption & 1330 & 4320 & 2320 & $82 \cdot 9$ & $10 \cdot 6$ \\
\hline Sturgeon-liver oil non-sap. & 1000 & 2500 & 1250 & $81 \cdot 4$ & $10 \cdot 6$ \\
\hline Adsorption (middle fraction) & 1100 & 2850 & 1470 & $81 \cdot 9$ & $10 \cdot 6$ \\
\hline Repeat adsorption & 835 & 2160 & 1430 & $81 \cdot 7$ & $10 \cdot 9$ \\
\hline Sturgeon-liver oil non-sap. distillate & 1330 & 4200 & 2130 & $\begin{array}{l}82 \cdot 8 \\
82 \cdot 6\end{array}$ & $\begin{array}{l}10 \cdot 9 \\
10 \cdot 7\end{array}$ \\
\hline After adsorption (middle layer) & $\begin{array}{c}\text { Fine } \\
\text { structure }\end{array}$ & 1950 & 1600 & $\begin{array}{l}85 \cdot 8 \\
85 \cdot 5\end{array}$ & $\begin{array}{l}10 \cdot 6 \\
10 \cdot 5\end{array}$ \\
\hline Mammalian-liver oil non-sap. & 1000 & 2750 & 1370 & $82 \cdot 4$ & $11 \cdot 1$ \\
\hline After adsorption (middle layer) & 1300 & 3810 & 1995 & $83 \cdot 1$ & $11 \cdot 0$ \\
\hline Repeat adsorption (middle layer) & - & 1450 & 1140 & $\begin{array}{l}83 \cdot 1 \\
83 \cdot 4\end{array}$ & $\begin{array}{l}10 \cdot 3 \\
10 \cdot 4\end{array}$ \\
\hline Mammalian non-sap. distillate & 1250 & 3620 & 2350 & $82 \cdot 7$ & $11 \cdot 4$ \\
\hline Adsorption (middle and bottom fractions) & 1320 & 3920 & 2500 & $82 \cdot 8$ & $10 \cdot 9$ \\
\hline
\end{tabular}

Material
Halibut non-sap. (best distillate)
Another halibut non-sap. distillate
(after adsorption)
Sturgeon non-sap. (best distillate)
Mammalian non-sap. (after adsorption)
Mammalian non-sap. distillate
Prof. Karrer's halibut preparations
(Liverpool measurements)

which has been adduced by Heilbron, Gillam and Morton [1931] concerning the complex nature of the reaction of antimony trichloride remains unshaken, and no satisfactory explanation of the highly selective inhibition of the $617 m \mu$ band, a phenomenon which persists in the richest distillates, is yet forthcoming [Morton, 1932]. Even were this difficulty removed a further source of uneasiness arises in the variable intensity of the absorption band with head at $693 m \mu$ in the colour test. The values for this band for different purified concentrates are summarised in Table VI and whereas with sturgeon oil the band was clearly seen at all stages in the concentration at approximately one quarter of the intensity of the $617 m \mu$ band, with halibut-liver oils its intensity varied according to the starting material from one-tenth to onequarter of that of the $617 m \mu$ band. In the case of the mammalian concen- 
trates, which are otherwise indistinguishable from the richest liver oil concentrates, no selective absorption at $693 \mathrm{m \mu}$ could be observed either in the crude extract or in the purified distillates. It is thus difficult to resist the conclusion that even the richest concentrates so far obtained are liable to contain variable quantities of a substance which is chromogenic towards antimony trichloride but is different from vitamin A itself.

While this work was in progress two papers appeared by Karrer, Morf and Schöpp [1931, 1, 2] in which an account is given of the preparation of a vitamin concentrate which, according to Euler [1931] gives a Carr-Price value of 130,000 . The method employed by Karrer and his collaborators for the final concentration of the vitamin consisted in adsorption of the sterol-free unsaponifiable fraction of the liver oils of both halibut and Scombresox saurus (Saury Pike) on Merck's specially prepared alumina on the lines of Tswett's chromatographic analysis. The purified product, which the authors consider may be regarded as approximately homogeneous, was obtained as a pale yellow viscous oil which gave analytical results in good agreement with either the formula $\mathrm{C}_{20} \mathrm{H}_{30} \mathrm{O}$ (5 double bonds) or $\mathrm{C}_{22} \mathrm{H}_{32} \mathrm{O}$ ( 6 double bonds). On catalytic hydrogenation the vitamin was found to take up a volume of hydrogen equivalent to 4.9 mols calculated on a molecular weight of 286 . Treatment with ozone gave geronic acid, in amount indicating the presence of one ionone ring, whilst quantitative oxidation with permanganate and chromic acid produced acetic acid in amounts corresponding respectively to $9.7 \%$ and $16.3 \%$ C-methyl. From these results the authors favour formula (I) as probably representing the structure of vitamin $\mathbf{A}$.<smiles>CC(C=CC=CC=C(C)C(C)(C)C1(C)CCCC1C)=CCO</smiles>

The wide discrepancy between the Carr-Price value recorded by Euler [1931] for the purified vitamin of the above authors and the value of about 65,000 units given for our distilled preparations led us to question whether the distillation method was in reality producing as rich a vitamin A concentrate as that obtained by the chromatographic process of fractionation. We therefore decided to test this method for ourselves, using the Merck "Fasertonerde" employed by Karrer and his colleagues. The apparatus used by us consisted of a long glass tube $T$ (Fig. 2) filled to a height of $75 \mathrm{~cm}$. with the fibrous alumina previously dried at $150-200^{\circ}$ in a current of carefully purified nitrogen. Nitrogen was first repeatedly drawn through the apparatus so as to ensure complete removal of air. A solution of the selected concentrate $(2.5 \mathrm{~g}$. in $25 \mathrm{cc}$. light petroleum) was then introduced at $S$ and the pressure reduced slightly so that on opening the cock $t_{3}$ it could be drawn into the adsorbing material. The solution, which penetrated the column to a depth of 
about $20 \mathrm{~cm}$. was now slowly washed down the whole column by introducing further quantities of light petroleum into $S$. The apparatus was then disconnected and the tube $T$ cut so that the adsorbent was divided into three equal parts. Each section was then separately extracted with hot methyl alcohol $(50 \mathrm{cc}$ ) $)$, the extract diluted with distilled water $(200 \mathrm{cc}$.) and the vitamin re-extracted with light petroleum.

Table $\mathrm{V}$ gives a summary of the results obtained in applying this method of purification to sterol-free vitamin A concentrates. It will be seen that

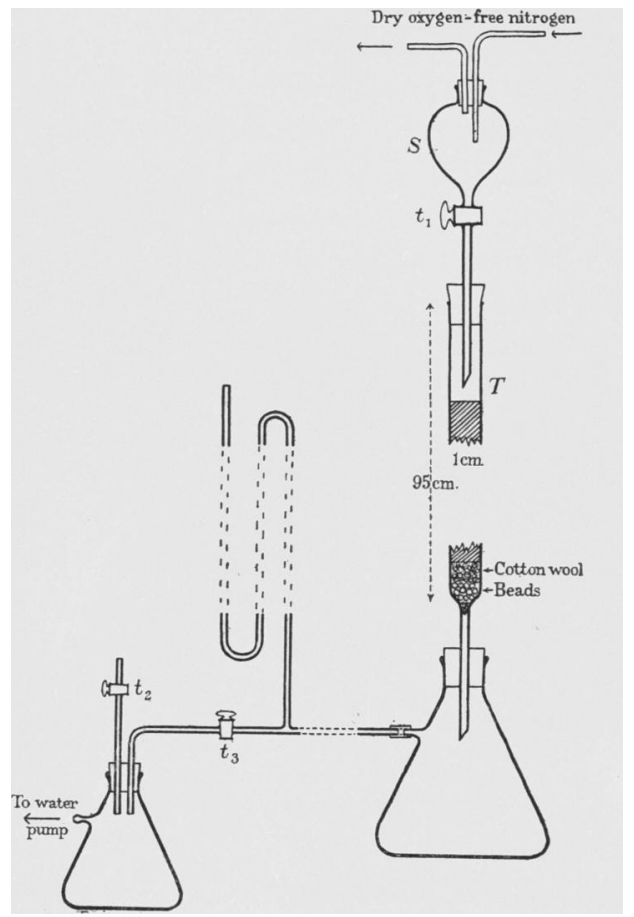

Fig. 2. Apparatus used in the experiments on selective adsorption.

although very definite concentration of the vitamin is effected the results prove that the method possesses no real advantage over that of distillation in a high vacuum. In our experience the method is only applicable to small quantities of material, and further, as measured spectroscopically, the effects of a second fractionation are scarcely, perceptible. The increase from 9100 to 10,500 C.L.O. units recorded by Karrer, Morf and Schöpp [1931, 1, 2] as a result of a second adsorption treatment of this concentrate is more probably due to the removal of traces of inhibitors, which, as is well known, greatly modify the blue colour reaction, than to a significant increase in the vitamin A content.

In order to ascertain finally whether the adsorption method was capable 
of effecting concentration beyond the highest point attained by distillation we have submitted the main distillates both from the halibut- and the sturgeonliver oils to the chromatographic process, and have observed either a definite loss of potency or a complete failure to raise the potency beyond the point $E_{1 \mathrm{~cm} .}^{1 \%} 328 m \mu=1350$. In the case of the richest sturgeon distillate the application of adsorption actually effected an obvious decomposition of the vitamin as evidenced by the appearance of fine structure in place of the smooth $328 m \mu$ band (see Table V). This failure to enrich the product was also confirmed on a mammalian concentrate.

As our experiments on the purification of vitamin A by the chromatographic method failed to account for the discrepancies in the Carr-Price values previously referred to, we approached Prof. Karrer, who very kindly supplied us with two specimens of his richest concentrate. A detailed spectrographic examination of these proved that they do not differ appreciably, except as regards the intensity of the $693 \mathrm{~m} \mu$ band discussed elsewhere in this paper, from those prepared by us. The spectroscopic magnitudes for the richest vitamin A concentrates together with Prof. Karrer's two preparations are summarised in Table VI, from which it will be seen that the maximum value $\left(E_{1 \mathrm{~cm} .}^{1 \%} 328 \mathrm{~m} \mu\right)$ so far obtained is 1350 .

\section{Preparation of concentrates from cod-liver oil.}

Emphasis has already been laid on the necessity for using highly potent liver oils as starting materials if concentrates of the highest magnitude of potency are required. That these conditions must be strictly observed is well exemplified in Table VII, where the results of applying the adsorption method of purification to a cod-liver oil initially several times as potent as an average specimen are recorded. After freeing the unsaponifiable matter from sterol by cooling to $-50^{\circ}$ the potency does not exceed one-third of the maximum value. Fractional adsorption on alumina gives in the first separation the fraction of

\section{Table VII.}

$\begin{array}{cl}\text { No. } & \text { Material } \\ 1 & \text { Cod-liver oil } \\ 2 & \text { Total non-sap. ( } 1.4 \% \text { approx.) } \\ 3 & \begin{array}{c}\text { Residue obtained after freezing } \\ \text { out sterol at }-10^{\circ}\end{array} \\ 4 & \text { Material frozen out at }-50^{\circ} \\ 5 & \text { Filtrate from (4) } \\ 6 & \text { Fractional adsorption of }(5) \text { on } \\ & \text { fibrous alumina: }\end{array}$

$\begin{array}{cccccc}328 m \mu & 617 m \mu & 580 m \mu & 693 m \mu & \% \text { C } & \% \text { H } \\ 4 \cdot 7 & 10 \cdot 4 & 7 \cdot 7 & - & - & - \\ 255 & 795 & 425 & 120 & - & - \\ - & 940 & 550 & 150 & - & - \\ - & 350 & .200 & - & - & - \\ 420 & 1350 & 800 & - & 79 \cdot 6 & 12.5\end{array}$
brous alumina:

(a) Top portion

(c) Bottom portion

$\overline{400} \quad 280$

$600 \quad 1780$

220
520

\section{$\overline{105}$}

1110

$\overline{81 \cdot 7} \quad \overline{10 \cdot 8}$

7 Second fractional adsorption using $6(c)$ :

(a) Middle portion

(b) Bottom portion

$\begin{array}{rrrr} & 1860 & 1250 & -\end{array}$

Biochem. 1932 XxvI 
highest potency in the bottom layer of the tube, and even after repetition of the purification process the potency fails to exceed about one-half the maximum value.

\section{Properties of distilled vitamin A.}

The distilled product (from all concentrates) forms a pale yellow viscous oil which becomes mobile on warming. It is readily soluble in organic solvents, somewhat more so in methyl than in ethyl alcohol. The vitamin, as obtained after distillation, is unexpectedly resistant to aerial oxidation but is highly susceptible towards acid media [Edisbury et al., 1932]. On standing, however, even in a sealed tube in the dark, a gradual decrease in potency occurs. Thus both with our best materials and that supplied by Prof. Karrer losses up to $10 \%$, as measured spectroscopically, occurred in less than a month. Analytical data for the highly active distillates and also for the concentrates prepared by the adsorption method where $E_{1 \mathrm{~cm} .}^{1 \%} 328 \mathrm{m \mu}$ has reached its highest value are given in Table VI, and it will be noted that the results on the whole are in fair agreement with the values required for $\mathrm{C}_{20} \mathrm{H}_{30} \mathrm{O}$. The carbon values of our preparations are somewhat lower than those recorded by Karrer, Morf and Schöpp [1931, 1,2] or found by us for Prof. Karrer's most active preparation, despite the fact that the absorption data are in outstandingly good agreement. In some cases distillation, while increasing the optically determined potency, seems to effect a slight decrease in the carbon percentage (compare Table III). An unexplained anomalous result was obtained with the sturgeon-oil distillate, which, when an attempt was made to purify it further by adsorption on alumina, gave a resin of low vitamin potency, the carbon value for which, however, was considerably higher than that found for the untreated distillate (Table V). Molecular weight determinations were carried out with the distillate from each species examined according to the Smith and Young modification [1927] of the Rast micromethod and gave as a mean result the value 312 , whereas cryoscopic determinations using benzene as solvent gave a mean value of 327 . These results are in good agreement with the value of 330 obtained by Karrer by the Rast method, and with the value of 333 calculated by Bruins, Overhoff and Wolff [1931] based on diffusion experiments (mol. wt.: $\mathrm{C}_{20} \mathrm{H}_{30} \mathrm{O}, 286 ; \mathrm{C}_{22} \mathrm{H}_{34} \mathrm{O}, 314$ ).

\section{Hydrogenation.}

Whereas crude vitamin A concentrates are strongly resistant to catalytic hydrogenation, the distilled products can be hydrogenated fairly readily using either palladium or Adams's platinum oxide. The absorption is rapid up to the point when about two-thirds of the total hydrogen is absorbed, after which the rate slows down considerably, and hydrogenation is completed only after many hours and with addition of fresh catalyst. In our experiments we have found that the volume of hydrogen absorbed corresponds to 4.5 molecules, based on $\mathrm{C}_{20} \mathrm{H}_{30} \mathrm{O}$ (5 double bonds) or 4.9 on the less probable $\mathrm{C}_{22} \mathrm{H}_{32} \mathrm{O}$ (6 double bonds) formula. Analysis of the crude hydrogenation pro- 
duct gave, in the case of two halibut distillates and the mammalian distillate, the following values respectively: (a) $\mathrm{C}, 79 \cdot 9 ; \mathrm{H}, 13 \cdot 3 ;(b) \mathrm{C}, 79 \cdot 8 ; \mathrm{H}, 13 \cdot 1$; (c) $\mathrm{C}, 80.9 ; \mathrm{H}, 12.8 \%$. In the case of $(b)$, fractional distillation in a high vacuum gave a main fraction, B.P. $168-172^{\circ} / 0.06 \mathrm{~mm}$., and a small amount of a higher boiling fraction, B.P. $180-210^{\circ} / 0.08 \mathrm{~mm}$., from which crystalline material separated on long standing. The solid was removed by filtration and after crystallisation from methyl alcohol was obtained as a colourless wax, M.P. $50-53^{\circ}$ (Found C, $75 \cdot 6,75 \cdot 8 ; \mathrm{H}, 13 \cdot 0,12.9 \%$ ). The quantity of this material at our disposal was unfortunately too small to allow of its further investigation but it is our intention to study the hydrogenation of larger quantities of distilled vitamin A so soon as fresh starting material becomes available. The main liquid distillate was tested with tetranitromethane and found still to be slightly unsaturated, as evidenced by the production of a definite yellow colour. It was accordingly rehydrogenated in acetic acid solution with Adams's platinum oxide, when a further quantity of hydrogen was absorbed. The product was again distilled in a high vacuum, and distilled almost wholly at $158-163^{\circ} / 0 \cdot 04 \mathrm{~mm}$. No colour was given with tetranitromethane, and the product, which was obtained as a thick colourless oil, was again analysed. (Found: $\mathrm{C}, 81 \cdot 3 ; \mathrm{H}, 13 \cdot 0 ; \mathrm{C}_{20} \mathrm{H}_{40} \mathrm{O}$ requires $\mathrm{C}, 81 \cdot 0 ; \mathrm{H}, 13 \cdot 6 \%$.)

\section{Iodine values.}

A series of iodine values was determined according to Rosenmund and Kuhnhenn's method [1923] and gave 306, 315, 324 on three different samples. (Iodine value for $\mathrm{C}_{20} \mathrm{H}_{30} \mathrm{O}$ (5 double bonds), 448.) It would seem from these results that the reagent attacks the ethylene linkage of the ionone ring only extremely slowly if at all. Evidence in favour of this assumption may be adduced from experiments on $\beta$-ionone when the following results were obtained: (a) 5 min. contact with Br reagent 198, 190, (b) 20 min. 190, 196, (c) 60 min. 231, 234. (Iodine value for $\mathrm{C}_{13} \mathrm{H}_{21} \mathrm{O}$ (2 double bonds), 264.)

\section{Preparation of esters.}

Karrer, Morf and Schöpp [1931,2] have described the preparation of a $p$-nitrobenzoate and an acetate of vitamin A, neither of which is recorded as having been obtained crystalline. We have ourselves prepared a benzoate by the following method. $15 \mathrm{~g}$. of halibut concentrate were dissolved in pure dry pyridine $(25 \mathrm{~g}$.) and freshly distilled benzoyl chloride ( $14 \mathrm{~g}$.) slowly added to the solution. After standing at room temperature for some time, the mixture was heated for 1 hour on a water-bath at $80^{\circ}$ in an atmosphere of nitrogen. After cooling, the solution was diluted with water, extracted with ether, and the ethereal extract repeatedly washed successively with dilute sodium carbonate solution and water, and dried over anhydrous sodium sulphate. The deep yellow, thick oil obtained after removal of solvent was repeatedly extracted with hot methyl alcohol until the extracts were no longer coloured. The residual oil $(6 \cdot 2 \mathrm{~g}$.) was taken up in ether, dried, and after removal of 
solvent subjected to high vacuum distillation when, as shown in Table VIII, a main fraction was collected distilling between 188 and $198^{\circ}$ without noticeable decomposition. The distilled benzoate formed a pale yellow viscous oil which could not be induced to crystallise. (Found: $\mathrm{C}, 82 \cdot 2 ; \mathrm{H}, 9 \cdot 2 \% \cdot \mathrm{C}_{20} \mathrm{H}_{29} \mathrm{O} . \mathrm{COC}_{6} \mathrm{H}_{5}$ requires $\mathrm{C}, 83.0 ; \mathrm{H}, 8.7 \%$.) Attempts have also been made to prepare solid esters using dinitrobenzoyl chloride, diphenic anhydride, phthalic anhydride and the acid chloride of anthraquinone-1-carboxylic acid, without success. Further experiments are now being carried out on these lines in the hope of obtaining solid derivatives of the hydrogenated alcohol or its oxidation products.

Table VIII.

\begin{tabular}{|c|c|c|c|c|c|c|c|c|}
\hline \multirow[b]{2}{*}{ Material } & \multirow[b]{2}{*}{$\begin{array}{l}\text { Temp. of } \\
\text { distillation }\end{array}$} & \multirow{2}{*}{$\begin{array}{c}\text { Time } \\
\text { of } \\
\text { distil- } \\
\text { lation; } \\
\text { min. }\end{array}$} & \multicolumn{3}{|c|}{$E_{1 \mathrm{~cm}}^{1 \%}$} & \multirow{2}{*}{$\begin{array}{l}\text { Carr- } \\
\text { Price } \\
\text { blue } \\
\text { value }\end{array}$} & \multicolumn{2}{|c|}{ Analysis } \\
\hline & & & $328 m \mu$ & $617 m \mu$ & $580 m \mu$ & & $\% \mathrm{C}$ & $\% \mathrm{H}$ \\
\hline $\begin{array}{l}\text { Halibut-liver oil con- } \\
\text { centrate used }\end{array}$ & - & - & 1150 & 3020 & 1450 & 57,000 & $84 \cdot 2$ & $11 \cdot 3$ \\
\hline $\begin{array}{l}\text { Total benzoylated } \\
\text { product }\end{array}$ & - & - & 710 & 1720 & 860 & - & $\begin{array}{l}82 \cdot 1 \\
82 \cdot 3\end{array}$ & $\begin{array}{l}8 \cdot 7 \\
9 \cdot 0\end{array}$ \\
\hline $\begin{array}{l}\text { Benzoylated product } \\
\text { (insol. in methyl } \\
\text { alcohol) }(6 \cdot 2 \mathrm{~g} .)\end{array}$ & - & - & 750 & 1920 & 910 & 40,000 & - & - \\
\hline $\begin{array}{l}\text { After high vacuum } \\
\text { distillation: } \\
\text { Fraction: }\end{array}$ & & & & & & & & \\
\hline (1) $0.2 \mathrm{~g}$. & $165-180^{\circ}$ & - & $\begin{array}{l}\text { Quanti } \\
\text { full }\end{array}$ & ty too sn & iall for & & & \\
\hline $\begin{array}{l}\text { (2) } 1.5 \mathrm{cc} . \\
\text { (3) } 2.5 \mathrm{cc} .\end{array}$ & $\begin{array}{l}170-190^{\circ} \\
195-198^{\circ}\end{array}$ & $\begin{array}{l}20 \\
60\end{array}$ & $\begin{array}{l}780 \\
780\end{array}$ & $\begin{array}{l}2020 \\
2250\end{array}$ & $\begin{array}{l}1010 \\
1200\end{array}$ & $\begin{array}{l}34,000 \\
37,000\end{array}$ & $\overline{82 \cdot 2}$ & $\overline{9 \cdot 2}$ \\
\hline (4) $0.3 \mathrm{~g}$. & Over $200^{\circ}$ & - & 290 & 550 & 345 & 15,000 & - & - \\
\hline (5) 0.7 g. residue & $\begin{array}{l}\text { Not volatile } \\
\text { at } 300^{\circ}\end{array}$ & - & $\begin{array}{c}145 \\
(300 \mathrm{at} \\
280 m \mu)\end{array}$ & 105 & 160 & - & - & - \\
\hline
\end{tabular}

Ozonisation.

We have repeated the ozonisation experiments described by Karrer, Morf and Schöpp [1931, 1, 2] using a halibut-liver oil distillate. Working under the conditions specified by the above authors we have isolated geronic acid in the form of its semicarbazone, which after recrystallisation from ethyl acetate was obtained in colourless needles, M.P. $163-163 \cdot 5^{\circ}$. The isolation of this acid fully confirms the presence of the ionone ring in the vitamin A structure [see also Heilbron, Morton and Webster, 1932].

Biological potency of the vitamin concentrates.

The physiological potency of certain of the distillates was tested by administration of measured amounts to young rats which had been fed upon a basal diet deficient in vitamin A until growth had ceased. The composition of the ration was

$\begin{array}{llllr}\text { Purified caseinogen } & \ldots & \ldots & 20 \\ \text { Rice starch } & \ldots & \ldots & \ldots & 80 \\ \text { Salt mixture } & \ldots & \ldots & \ldots & 5 \\ \text { Dried yeast } & \ldots & \ldots & \ldots & 5\end{array}$


Vitamin D was supplied by the separate administration of $0.001 \mathrm{mg}$. of a tested preparation of irradiated ergosterol twice weekly. Both this supplement and the fractions being tested for vitamin A potency were given in the form of solutions in freshly-distilled ethyl laurate. The test solutions of vitamin A concentrates were made up twice weekly and were stored at low temperature in the dark.

The concentrate prepared from halibut-liver oil and fractionated by distillation $\left(E_{1 \mathrm{~cm} .}^{1 \%} 328 \mathrm{m \mu}=1300\right)$ promoted growth in doses of $0 \cdot 1 \gamma$ daily and cured xerophthalmia in 48 hours (Fig. 3). Smaller doses of this concentrate were not tested but in the case of the distilled concentrate from the sturgeonliver oil an improvement in general condition and a slow resumption of growth occurred when daily doses as low as $0.025 \gamma$ were given. A dose of $0.05 \gamma$ of this material effected a rapid cure of the eye disease in one rat (Fig. 4). These materials would appear to have a higher biological activity than those tested

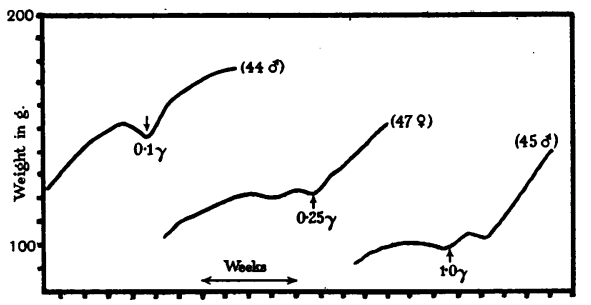

Fig. 3.

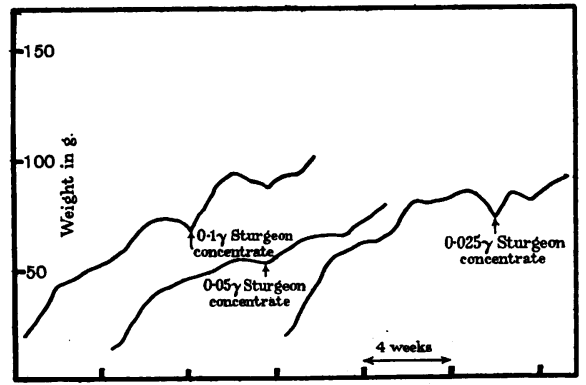

Fig. 4.

Fig. 3. Biological tests on main fraction obtained by distillation of Halibut-liver oil concentrate.

Fig. 4. Showing recovery of growth caused by administration of concentrate of vitamin A prepared from sturgeon-liver oil. Basal diet throughout deficient in vitamin A.

by Euler [1931], Karrer, Morf and Schöpp [1931, 1, 2] and Euler and Karrer [1931], although the differences may to some extent be due to different methods of conducting the feeding experiments.

\section{Discussion.}

The position which has now definitely been reached is that the richest products obtained both by us and by Karrer and his collaborators, from mammalian and various fish-livers, are qualitatively and quantitatively indistinguishable in respect of ultra-violet absorption. If the products are not homogeneous, then either the non-vitamin material is relatively diactinic, or the preparations contain substances so closely alike that both exhibit the $328 \mathrm{~m} \mu$ band. The absorption spectrum affords no conclusive criterion of homogeneity although it would be indeed curious if exactly the same proportion of material exhibiting negligible absorption were present in the products derived from various species of fish. On the other hand, the discovery of isomeric $\alpha$ - and $\beta$-carotenes, both transformed in vivo into vitamin A-like 
substances [Kuhn and Brockmann, 1931] suggests plainly that strict homogeneity must be demonstrated rather than assumed.

If the ultra-violet absorption spectrum leaves the question of purity an open one, the antimony trichloride colour test is equally indecisive. Even if the difficult choice concerning the origin of the 617 and $583 \mathrm{~m} \mu$ maxima can be resolved by the demonstration (which is yet to seek) that both bands are traceable to one entity, the existence of the maximum at $693 \mathrm{~m} \mu$ and especially (as shown in Table VI) its variable intensity in different preparations, remains wholly unexplained.

Our own observations in general are at least as consistent with Prof. Karrer's tentative structure (I) for vitamin A as with any alternative, and indeed the weight of evidence is impressively though not conclusively in its favour.

From the standpoint of analytical data, the failure to prepare crystalline derivatives of vitamin A makes it very difficult to compel assent to any claims to having prepared the vitamin in a state of purity. The experimental data on molecular weights lead to a value of $320 \pm 15$ as against 286 on the basis of the formula. In itself, this small discrepancy is not necessarily significant, but when the results of a very large number of ultimate analyses uniformly indicate variable values not quite consistent with the $\mathrm{C}_{20} \mathrm{H}_{30} \mathrm{O}$ formula, doubts concerning purity are strengthened. Finally, our experiments on fully hydrogenated preparations have provided definite evidence of some contaminant in the resulting product.

The analytical data show that the question at issue is not, however, one of gross impurity, and further the extinction coefficient of the $328 \mathrm{m \mu}$ band is of the correct order to be expected from the proposed constitution. In this connection it must be borne in mind that neither $\mathrm{C}$ and $\mathrm{H}$ percentages nor molecular weights would be affected by heterogeneity arising out of isomeric forms.

As far as can be judged, a small quantity of an alcohol, probably more saturated than vitamin $\mathbf{A}$, is extremely difficult to eliminate completely when reasonably large quantities of material are under investigation. This probably accounts for the failure to reach the highest potency when the full technical resources are applied to cod-liver or poor grade halibut-liver oils.

Once the remaining doubts concerning homogeneity are resolved, biological, spectroscopic and colorimetric standards can be set up in terms of which the results of various methods of assay can be expressed.

We desire to express our thanks to the Department of Scientific and Industrial Research for grants to two of us (R.N.H. and E.T.W.) in aid of this investigation. We are also deeply indebted to Dr J. A. Lovern of the Torry Research Station, Aberdeen, for the great help he has given us in the collection of fish-liver oils, to Messrs Lever Brothers, Ltd., for placing at our disposal samples of mammalian concentrates, to Dr F. H. Carr and Mr W. Jewell of 
British Drug Houses, Ltd., for carrying out the vitamin distillations, and to Mr W. Doran and Mr W. F. Boston of Liverpool University for carrying out the numerous micro-analyses recorded in this paper. Part of the expenses of this investigation was defrayed by a grant from the Medical Research Council, for which we express our thanks.

\section{REFERENCES.}

Bruins, Overhoff and Wolff (1931). Biochem. J. 25, 430.

Drummond and Baker (1929). Biochem. J. 23, 274.

Edisbury, Gillam, Heilbron and Morton (1932). Biochem. J. 26, 1164.

Euler (1931). Chemistry at the Centenary Meeting of the British Association, p. 92.

— and Karrer (1931). Helv. Chim. Acta, 14, 1040.

Heilbron, Gillam and Morton (1931). Biochem. J. 25, 1352.

- Morton and Webster (1932). Biochem. J. 26, 1194.

Karrer, Morf and Schöpp (1931, 1). Helv. Chim. Acta, 14, 1036.

$-1(1931,2)$. Helv. Chim. Acta, 14, 1431.

Kuhn and Brockmann (1931). Ber. deutsch. chem. Ges. 64, 1859.

Morton (1932). Biochem. J. 26, 1197.

- Heilbron and Thompson (1931). Biochem. J. 25, 20.

Rosenmund and Kuhnhenn (1923). Z. Nahr. Genussm. 46, 154.

Smith and Young (1927). J. Biol. Chem. 75, 289.

Note added August 16th, 1932. Since this paper was written we have received (7. vi. 32) a fresh halibut oil the vitamin A content of which was approximately double that of the richest oil ( $e$ in Table I) previously examined. The following table shows the potencies at various stages in the extraction of the vitamin. Although the original oil was phenomenally rich in vitamin A (estimated at $10 \%$ vitamin) the final product was not appreciably different from the values recorded in Table VI.

\begin{tabular}{|c|c|c|c|c|c|c|}
\hline \multirow[b]{2}{*}{ Material } & \multicolumn{4}{|c|}{$E_{1 \mathrm{~cm} .}^{1 \%}$} & \multicolumn{2}{|c|}{ Analysis } \\
\hline & $328 m \mu$ & $617 m \mu$ & $580 \mathrm{m \mu}$ & $693 m \mu$ & C \% & $\mathrm{H} \%$ \\
\hline Halibut-liver oil & 164 & 430 & 260 & 50 & - & - \\
\hline $\begin{array}{l}\text { Non-sap., filtrate } \\
-60^{\circ}\end{array}$ & - & 4000 & 2000 & 410 & $\left\{\begin{array}{l}82 \cdot 4 \\
82 \cdot 7\end{array}\right.$ & $\begin{array}{l}10 \cdot 6 \\
10 \cdot 5\end{array}$ \\
\hline $\begin{array}{l}\text { Ditto after adsorption } \\
\text { (i) } \\
\text { (ii) }\end{array}$ & $\overline{1350}$ & $\begin{array}{l}3950 \\
4520\end{array}$ & $\begin{array}{l}2100 \\
2360\end{array}$ & $\begin{array}{l}560 \\
270\end{array}$ & $\overline{83 \cdot 3}$ & $\overline{10 \cdot 7}$ \\
\hline Distillate, B.P. $136^{\circ}$ & 1370 & 4650 & 2550 & 450 & $83 \cdot 3$ & $11 \cdot 0$ \\
\hline
\end{tabular}

